\title{
Relações entre Estado e empresários no PDE/PAR: algumas contradições na política educacional brasileira
}

Relations between the State and entrepreneurs in PDE/PAR: some contradictions in the brazilian educational policy

Relaciones entre el Estado y los empresarios de la PDE/PAR: algunas contradicciones en la política educativa brasileña

\section{ALEXANDRE JOSÉ ROSSI \\ LIANE MARIA BERNARDI LUCIA HUGO UCZAK}

Resumo: Este artigo apresenta discussões sobre como o setor privado mercantil influencia as políticas educacionais brasileiras. $\mathrm{O}$ artigo expõe relações entre o Movimento Todos pela Educação e as políticas educacionais públicas, revelando suas similitudes. Evidenciamos como a classe empresarial influencia o setor público na criação de políticas e, ao mesmo tempo é cliente do Estado, ofertando tecnologias educacionais; articula se em torno de consensos de propostas educacionais junto ao governo federal, naturalizando a incorporação da associação entre o público e o privado.

Palavras-chave: Movimento Todos pela Educação; políticas educacionais; público-privado; classe.

\begin{abstract}
This article presents discussions about how the private sector influences Brazilian education policies. The article exposes the similarities between the movement Everyone for the Education and the similarities with the Public Educational Policies. In this paper, we emphasize that the private sector influences the public education on the creation of policies and, at the same time, is a client of the State, offering educational technologies that are structured around proposals in consensus with the Federal Government, naturalizing the incorporation of the public-private relationships.
\end{abstract}

Keywords: Everyone for the Education Moviment; educational policies; publicprivate; class.

Resumen: Este artículo presenta discusiones sobre como el Sector Privado mercantil influencia en las Políticas Educativas brasileñas. El artículo expone las relaciones entre el Movimiento Todos por la Educación y las similitudes con las políticas educativas públicas. Mostramos como la clase empresarial influye en el Sector Público en la creación de políticas y, al mismo tiempo es cliente del 
estado, ofreciendo tecnologías educativas se articula alrededor de consensos de propuestas educativas junto al gobierno federal, naturalizando incorporándola incorporación de la asociación entre lo público y lo privado.

Palabras clave: Movimiento Todos por la Educación; políticas educativas; el sector público y privado; clase.

\section{INTRODUÇÃO}

Neste artigo apresentamos discussões sobre como o setor privado mercantil adentra as políticas educacionais brasileiras, demarcando sua posição de classe na construção de políticas públicas, com o objetivo de mostrar o modo como a classe empresarial influenciou algumas políticas, como o Plano de Desenvolvimento da Educação e o Plano de Ações Articuladas (PDE/PAR), o Plano Nacional de Educação (PNE), as alterações na Lei de Diretrizes e Bases da Educação Nacional, dentre outras.

A partir da metodologia de análise documental, apresentamos o movimento empresarial, observando sua atuação, seu discurso e sua proposta de ação até a incorporação de elementos desta, traduzida em políticas públicas pelo governo federal.

A base material da pesquisa traz os dados coletados no site do Movimento Todos pela Educação, nos sites relacionados a empresas e empresários que compõem o Movimento e nos principais documentos disponibilizados pelo MEC sobre as políticas acima citadas. A sustentação teórica do estudo respalda-se nos argumentos de Peroni (2011), Laval (2004), Gale (2003), Shiroma, Garcia e Campos (2011), Thompson (1987), Gramsci (2002), Wood (2003), Ball e Olmedo (2013), Voss (2011) e ainda Evangelista e Leher (2012).

O artigo organiza-se em três seções: (i) Alguns Apontamentos Teóricos e Metodológicos, em que apresentamos de forma breve os pressupostos que sustentam nossas análises; (ii) O Movimento Empresarial Todos pela Educação: sujeitos e relações, quando são apresentadas suas propostas para educação; (iii) Do TPE ao Compromisso Todos pela Educação: interlocução e hegemonia do movimento empresarial na política educacional brasileira, seção em que fizemos aproximações entre as metas do TPE e algumas políticas educacionais brasileiras. 


\section{APONTAMENTOS TEÓRICOS E METODOLÓGICOS}

Entendemos a definição de classe a partir de Thompson (1991) que não a vê como uma categoria ou estrutura, mas como um processo, como algo que ocorre e pode ser demonstrado nas relações humanas e que unifica a experiência e a consciência. Ellen Wood, ao dialogar com a obra de Thompson, afirma que "as formações de classe e a descoberta da consciência de classe se desenvolvem a partir do processo de luta, à medida que as pessoas 'vivem' e 'trabalham' suas situações de classe" (WOOD, 2003, p.76). Ou seja, a classe é um "fenômeno visível apenas no processo" (Idem, p. 77).

Para Thompson (1987) a classe acontece quando homens e mulheres "sentem e articulam a identidade de seus interesses entre si e com outros homens, cujos interesses diferem (e geralmente se opõem) dos seus" (p.10). Nesse sentido, a consciência de classe surge de configurações diferentes e pode ser considerada a forma como as experiências são tratadas, como elas se materializam em valores, ideias e instituições. Só podemos ver o movimento de classe como uma formação social e cultural que opera num dado período histórico e consideramos que ele não é estático; ao contrário, está sempre mudando.

Assim agregamos a esta reflexão os elementos da luta de classes e a correlação de forças que se estabelece numa sociedade para que, a partir disso, compreenda-se o "grau de homogeneidade e de organização alcançada pelos diversos grupos sociais" (GRAMSCI, 2002, p. 40). A pressão resultante da tensão de determinados grupos tende a diminuir, porém ela não se extingue quando se constrói o consenso, que, para Gramsci, pode ocorrer a partir de duas possibilidades: “como 'domínio' e como ‘direção intelectual e moral” (GRAMSCI, 2002, p. 62).

A criação da hegemonia não é algo abstrato, mas produzido através da disputa entre grupos e classes sociais. E, para Gramsci (2002), “através do 'direito' o Estado torna 'homogêneo' o grupo dominante e tende a criar um conformismo social que seja útil à linha de desenvolvimento do grupo dirigente" (p. 240). No entanto, entendemos que existem correlações de forças disputando o Estado e a formação de consensos.

Considerando esses elementos, podemos afirmar que a classe trabalhadora brasileira conquistou o acesso à educação, fruto de muita luta, mas a consolidação do acesso, da permanência e da qualificação desse processo está em disputa. Quando se percebe que, nas atuais políticas educacionais para a escola pública, existem interesses e influência dos empresários, e que o governo incorporou parcerias com esse grupo, é preciso atenção a esse movimento de classe e à criação desse consenso. 
Também precisamos ponderar sobre os interesses que a classe mercantil tem nesse processo, do ponto de vista de disputa de projeto societário, tanto no aspecto de determinar o conteúdo da proposta educacional quanto na possibilidade de ofertar produtos no Guia de Tecnologias Educacionais ${ }^{1}$ do Plano de Ações Articuladas/ PAR, ampliando as possibilidades de lucros, de influência ou de hegemonia.

Outra perspectiva é a definição de como estamos olhando as políticas; considerando que elas não são estáticas, observaremos o jogo que perpassa a política desde sua formulação até a execução, "a política da política” (GALE, 2003, p.122). Trevor Gale (2007) propõe que se observem as fronteiras e interfaces entre quem produz e quem implementa a política, quem tem permissão ou condições de estabelecer o quê e o como da política, como ocorre a coalizão de interesses, proposta que será adotada neste artigo.

Destacamos ainda que a política educacional é aqui entendida como uma política social. De acordo com Vieira (2007), as políticas sociais, enquanto estratégias governamentais, revelam-se na forma de relações jurídicas e políticas, o que implica dizer que elas não podem ser compreendidas por si mesmas: são uma forma de expressar as relações sociais as quais se manifestam através das relações de produção. Neste sentido, o autor adverte que

Os planos, os projetos, os programas, os documentos referentes em certo momento
à educação, à habitação popular, às condições de trabalho e lazer, à saúde pública,
à Previdência Social e até à Assistência Social não se colocam como totalidades
absolutas. E não se põem como totalidades absolutas enquanto esferas mais
amplas, com a denominação de política social [...]. Muito menos se põem como
totalidades específicas, que levam o nome de política educacional, habitacional, de
saúde, previdenciária ou assistencial (p. 142-3).

De acordo com as afirmações do autor, não se pode tomar programas e planos enquanto totalidades absolutas, ou seja, esses planos e programas são partes de uma totalidade maior. Rossi (2010) afirma que, ao analisá-los em um curso particular da história, faz-se necessário colocá-los em relação aos demais elementos da vida social, pois a política social por si mesma não se explica, ela precisa ser entendida dentro de um movimento maior, levando em consideração os aspectos políticos, socioculturais e econômicos.

Assim, entendemos o PDE/PAR, enquanto um programa de governo que é parte de uma totalidade maior - a política educacional - deve ser analisado na sua relação com os demais planos e políticas de governo e de Estado.

1 O Guia de Tecnologias Educacionais é um documento que contém a descrição de diversas tecnologias e informações suplementares acerca de materiais pedagógicos elaborados por instituições ou empresas públicas e/ou privadas e que são pré-qualificadas pelo MEC. 
O Plano de Desenvolvimento da Educação - PDE, conforme consta no site do governo federal, é um plano que prevê o desenvolvimento da educação no Brasil com o objetivo de investir na Educação Básica através de projetos que envolvam toda a comunidade escolar por meio de iniciativas que garantam o sucesso e a permanência com qualidade do aluno na escola.

Em 2007, os municípios considerados prioritários, ou seja, aqueles que apresentavam baixo Índice de Desenvolvimento da Educação Básica (IDEB), foram convocados e aderiram ao Plano de Metas Compromisso Todos Pela Educação ${ }^{2}$ e, então, estavam aptos a elaborarem o PAR, que é um planejamento multidimensional da política educacional que cada rede pública de educação deveria fazer para um período de quatro anos. Posteriormente, todos os 5.563 municípios, os 26 estados e o Distrito Federal puderam aderir ao programa e elaborar o seu planejamento.

Ao observarmos o movimento do PAR, desde sua discussão, constituição e implementação ${ }^{3}$, destacamos a forte presença do setor empresarial, em especial do Todos pela Educação, disputando o conteúdo da política e ofertando serviços e produtos educacionais.

Nas próximas sessões, faremos aproximações entre o Movimento empresarial Todos pela Educação e as políticas educacionais, destacando as relações estabelecidas através do PDE/PAR, evidenciando as contradições e as disputas pelo consenso e pela hegemonia desse processo.

\section{MOVIMENTO EMPRESARIAL TODOS PELA EDUCAÇÃO: SUJEITOS E RELAÇÕES}

O setor privado sempre esteve presente no setor público no Brasil ${ }^{4}$, mas, ao longo do tempo, essa presença foi assumindo diferentes formas. Se observarmos a partir dos anos de 1990, veremos que os empresários brasileiros organizaram fóruns e documentos em que apontaram interesse na construção de uma agenda educacional voltada à "produção de uma nova sociabilidade, mais adequada aos interesses privados do grande capital nacional e internacional" (SHIROMA, GARCIA, CAMPOS, 2011, p. 227). Nessa ótica, propuseram reformar a educação e a escola, tornando-a mais eficaz às novas demandas do capital, formando um trabalhador que dominasse as novas competências tecnológicas e organizacionais.

\footnotetext{
2 Para maiores detalhes sobre PDE/PAR ver ROSSI, A. J.; BERNARDI, L. M.; UCZAK, L. H (2013)

3 Ver CAMINI (2013), MARTINS (2016), VOSS (2011).

4 Sobre o histórico do público e privado na educação brasileira, ver PIRES (2015).
} 
Além de propor a importação da eficácia do modelo empresarial, pretendiam "repor a função social da educação e da escola destituindo-as, contudo, do seu caráter público" (ibidem).

Empregando o discurso de 'educação para todos e todos pela educação' incorporaram e ressignificaram históricas reivindicações daluta pela democratização da educação, dando-lhes outra perspectiva. Apresentaram propostas em nome da melhoria da qualidade da educação, defendendo a ampliação da jornada escolar, a universalização do atendimento, as propostas de avaliação em larga escala, os incentivos à realização de parcerias externas buscando apoio às atividades educacionais, entre outras questões. Esse discurso da qualificação e da ampliação da escolaridade constitui consenso na sociedade e refere-se a bandeiras históricas dos movimentos sociais. Os empresários, porém, incorporaram-nas, propondo uma forma diferente de executá-las, tendo por metodologia a gestão gerencial.

No Brasil, essa proposta de qualidade pautada pelo mercado foi defendida pelo movimento empresarial Todos pela Educação (TPE). Em 2006, realizou-se a Conferência Ações de Responsabilidade Social em Educação: melhores práticas na América Latina, promovida pela Fundação Lemann, Fundação Jacobs e Grupo Gerdau, com apoio do Programa de Reformas Educacionais para a América Latina (Preal). Esse "grupo de intelectuais orgânicos do capital" (SHIROMA; GARCIA; CAMPOS, 2011, p. 233) elaborou um documento sobre educação: o 'Compromisso Todos Pela Educação' e iniciou a realização de diversos eventos, propondo um grande pacto pela educação com os sindicatos, com a sociedade educacional e civil e logo ganhou adesão da mídia. "Os empresários se antecipam e pautam a agenda governamental: reafirmam o papel do Estado redefinindo, no entanto, o sentido e o significado da educação pública" (idem, p. 226). O Movimento propõe a mobilização da iniciativa privada e das organizações sociais do terceiro setor para atuar junto com o Estado no provimento da educação.

Todas essas propostas dos empresários convergem com as reformas educacionais implementadas em vários países europeus e latino-americanos a partir da década de 1990, bem como com as orientações da Conferência Mundial de Educação Para Todos de Jomtiem, da qual o Brasil é signatário, que elaborou a Declaração Mundial de Educação Para Todos (Education For All). O EFA reafirmou a educação para toda vida, defendeu a expansão da escolaridade e a importância das avaliações em larga escala para o sucesso da integração na sociedade e afirmou que, para isso, as agências internacionais e o setor privado, junto com a sociedade civil, devem trabalhar em conjunto para alcançar esses objetivos.

Segundo o ex-ministro da educação, Paulo Renato Souza, o fato de o setor privado organizar eventos para discutir como melhorar os sistemas educacionais da região latino-americana constitui-se uma novidade. Ao explicar as razões para 
as proposições dos empresários, Souza associa-se aos argumentos dos teóricos neoliberais, afirmando que tal iniciativa é indicativa de que "o Estado sozinho não é capaz de resolver esses graves problemas num período curto de tempo" (SOUZA, 2006). O argumento da ineficiência do Estado tem sido utilizado para justificar a necessidade da intervenção dos empresários nas questões sociais e ao mesmo tempo para dar visibilidade às 'propostas salvadoras' recomendadas pelo setor privado.

O TPE foi convocado pela financeira Banco Itaú Unibanco Participações S.A. em parceria com empresários do país, e se apresentou como uma iniciativa da sociedade civil, "Que que tem como missão contribuir para que, até 2022, ano do bicentenário da Independência do Brasil, o País assegure a todas as crianças e jovens o direito à Educação Básica de qualidade”. (TPE, 2015). Porém, compartilhamos o entendimento de que constitui, "de fato, como uma rede política que congrega agentes sociais, intelectuais, empresas, instituições públicas e privadas e grupos de interesses heterogêneos, articulados em torno de um discurso comum" (VOSS, 2011, p. 52). A maioria dos integrantes não provém do campo da educação; são "profissionais ligados à economia, à administração, à comunicação, ao mundo dos negócios ou são pessoas que ocuparam determinados cargos políticos nos governos federal ou estaduais" (ibidem).

Capitaneado pelo setor financeiro e articulado com o setor empresarial, o Movimento fez a convocação para a intervenção na educação e, como afirmam Olinda Evangelista e Roberto Leher, isso

\footnotetext{
Partiu da constatação de que as corporações estavam atuando em centenas de grandes projetos educacionais com objetivos educacionais pertinentes, afins aos interesses corporativos que os patrocinam, mas que a dispersão dos esforços impedia uma intervenção 'de classe' na educação pública, objetivo altamente estratégico, pois envolve a socialização de mais de 50 milhões de jovens, a base da força de trabalho dos próximos anos. Os setores dominantes, após a articulação política dos grupos econômicos em prol do movimento, passaram a atuar por meio de suas fundações privadas ou de suas Organizações Sociais, como Itaú- Social, Faça Parte, Ayrton Senna, Roberto Marinho, Gerdau, Victor Civita, Abril, Bunge, D'Pascoal, Bradesco, Santander, Vale, PREAL, Lemann, entre outros. (EVANGELISTA, LEHER, 2012, p.07)
}

André Martins (2009) ao discutir classe, afirma que surgiu uma nova força política na educação em que, através do TPE, os “intelectuais e as organizações do capital assumiram um papel ainda mais decisivo no processo de estabelecimento de bases políticas e sociais para legitimar a configuração mais recente do capitalismo em nosso país (p. 21), 
Consta no site do TPE que:

Em fevereiro de 2014 o Todos Pela Educação teve seu estatuto reformado para se qualificar como Organização da Sociedade Civil de Interesse Público (Oscip). Apartidário e plural, congrega representantes de diferentes setores da sociedade, como gestores públicos, educadores, pais, alunos, pesquisadores, profissionais de imprensa, empresários e as pessoas ou organizações sociais que são comprometidas com a garantia do direito a uma Educação de qualidade. (TPE, 2015 - grifos nossos).

Percebe-se que o discurso inicial de garantia do acesso à educação - que é um direito - é substituído pelo da 'qualidade', cujo sentido para esse grupo está na avaliação e construção de um parâmetro de qualidade pensado e definido pelo TPE e aceito socialmente. Sobre isso, Dulce Voss afirma que

O discurso da educação como fator estratégico de desenvolvimento social e econômico é atualmente recontextualizado, pois a ênfase central das reformas educacionais contemporâneas não é a expansão da escolarização, mas a equidade, entendida como a oferta eficiente e eficaz do ensino, de modo a garantir condições de aquisição de habilidades e informações que permitam competir no mercado profissional (VOSS, 2011, p. 45).

Ao retomarmos esse histórico de constituição do Todos pela Educação e o papel dos sujeitos, estamos embasados em Thompson (1981) quando afirma que não existe processo histórico sem sujeito, assim como também não existem sujeitos sem história. Destarte, entendemos o movimento TPE como sujeito coletivo que produz história, defendendo interesses particulares, articulados em torno de um projeto social. A prática do TPE, compreendido como sujeito histórico, é uma iniciativa de classe que se constituiu independente do Estado, mas que funciona articulando-se com o governo e com setores da educação no país. Desse modo, esse projeto determina o que vem a ser a qualidade da educação, "traduzindo-a sob a forma de subordinação à formação para o trabalho explorado requerido pelo capitalismo" (EVANGELISTA; LEHER, 2012, p.9).

No site do TPE constam cinco metas, cinco bandeiras e cinco atitudes para consolidar a proposta de ação dos empresários que, como já afirmamos, está incorporando o discurso das lutas dos movimentos sociais, mas não o seu conteúdo. As metas são:

Meta 1 Toda criança e jovem de 4 a 17 anos na escola [...] Meta 2 Toda criança plenamente alfabetizada até os 8 anos [...] Meta 3 Todo aluno com aprendizado adequado ao seu ano [...] Meta 4 Todo jovem com Ensino Médio concluído até os 19 anos [...] Meta 5 Investimento em Educação ampliado e bem gerido. (TPE, 2015). 
A partir dessas metas, o Movimento propõe a divulgação e o monitoramento da educação no país, passando a intervir nos parâmetros do que entende ser qualidade, divulgando amplamente o que considera gestão de sucesso, com uso das inovações didáticas padronizadas e replicáveis, além de tecnologias ofertadas por seus próprios parceiros. Incorporou a tarefa de monitorar o IDEB e o PNE, lançando suas cinco bandeiras:

1 - Formação e carreira do professor [...] 2 - Definição dos direitos de aprendizagem [...] 3 - Ampliação da exposição do aluno ao ensino [...] 4 - Uso relevante das avaliações na gestão educacional [...] 5 - Aperfeiçoamento da gestão e da governança da Educação (TPE, 2015).

Percebe-se que se avultam os discursos sobre maior tempo do aluno na escola, seja pela ampliação obrigatória de anos ou por mais horas diárias na instituição - princípios oriundos da luta pela educação pública - e também pelo aperfeiçoamento da gestão da educação. Em sua página, o TPE se define como produtor de conhecimento e agente mobilizador da sociedade; para tanto, produz campanhas, relatórios e boletins. Para o Movimento, a diferença está no método: é preciso avaliar e alcançar qualidade na educação, o que passa pelo ideário da "pedagogia dos resultados e na pedagogia das competências" (MARTINS, 2013, p.75) com produtividade mensurável.

Para realizar tal tarefa, o TPE se organiza numa estrutura de governança composta por colegiados, que atuam da seguinte forma: um Conselho de Governanç, composto por 16 a 20 integrantes, presidido por Jorge Gerdau Johannpeter; um Conselho Fiscal, com três integrantes ${ }^{5}$, e Comissão Técnica, com 15 integrantes, coordenados por Viviane Senna. Todos os integrantes listados são empresários, banqueiros ou consultores de empresas que, na mesma página do site, aparecem listados junto a outros nomes intitulados ‘sócios fundadores' do TPE. Nos limites deste artigo, destacaremos apenas o Conselho de Governança do Movimento Todos pela Educação, responsável por definir suas políticas, representado no quadro abaixo:

5 Fazem parte deste Conselho Gilberto Bagaiolo, Contador (Sócio da PWC Brasil), Junio Fuentes, consultor da Luzio Stategy Group, e Jaime Sirotsky, presidente do grupo RBS. 
Quadro 1- Conselheiros de Governança do Todos pela Educação e suas empresas

\begin{tabular}{|c|c|}
\hline NOME DO CONSELHEIRO & EMPRESA QUE REPRESENTA \\
\hline Jorge Gerdau Johannpeter & Presidente do Grupo Gerdau \\
\hline Ana Maria dos Santos Diniz & Instituto Grupo Pão de Açúcar \\
\hline Antonio Cesar Russi Callegari & $\begin{array}{l}\text { Diretor da Faculdade SESI-SP de Educação; Membro } \\
\text { do Conselho Nacional de Educação; Presidente do } \\
\text { Instituto Brasileiro de Sociologia Aplicada - IBSA }\end{array}$ \\
\hline Antonio Jacinto Matias & Voce-presidente da Fundação Itaú Social \\
\hline Beatriz Johannpeter & Instituto Gerdau \\
\hline Daniel Feffer & Susano Holding SA \\
\hline Danilo Santos de Miranda & Diretor Regional SESC SP \\
\hline Denise Aguiar Alvarez & Diretora Fundação Bradesco \\
\hline Fernão Carlos Botelho Bracher & $\begin{array}{l}\text { Itaú e Banco BBA Creditanstalt, ex-presidente do } \\
\text { Banco Central }\end{array}$ \\
\hline José Francisco Soares & $\begin{array}{l}\text { Professor da UFMG, membro do Conselho Técnico do } \\
\text { Instituto Nacional para la Evaluatión de la Educatión } \\
\text { (INEE) do México e ex presidente do INEP. }\end{array}$ \\
\hline José Roberto Marinho & Fundação Roberto Marinho- Rede Globo \\
\hline Luciano Dias Monteiro & $\begin{array}{l}\text { Diretor de Relações Institucionais do Grupo Santillana } \\
\text { Brasil (Editora Moderna) }\end{array}$ \\
\hline Luiz Norberto Pascoal & Grupo D'Pascoal e Fundação Educar D'Pascoal \\
\hline Luiz Paulo Saade Montenegro & Instituto Paulo Montenegro \\
\hline Milú Villela & Presidente do Instituto Faça Parte e Brasil Voluntário \\
\hline Mozart Neves Ramos & $\begin{array}{l}\text { Diretor de articulação e inovação do Instituto Ayrton } \\
\text { Senna }\end{array}$ \\
\hline Ricardo Henriques & $\begin{array}{l}\text { Superintendente executivo do Instituto Unibanco e Professor } \\
\text { do Departamento de Economia da Universidade Federal } \\
\text { Fluminense (UFF). }\end{array}$ \\
\hline Viviane Senna & Instituto Ayrton Senna \\
\hline Wanda Engel Aduan & Superintendente executiva do Instituto Unibanco \\
\hline
\end{tabular}

Fonte: arquivo próprio

Destacamos que alguns integrantes que atuam nesse conselho também já atuaram no governo, como é o caso de Ricardo Henriques, ex-secretário do SECADI/MEC que é o atual superintendente do Instituto Unibanco ou de Antonio Callegari que já foi Secretário de Educação Básica do MEC e responsável pela construção do Pacto Nacional pela Alfabetização na Idade Certa (2012), e José Francisco Soares que foi presidente do INEP. Outro destaque se refere ao fato de Jorge Gerdau ser membro do Conselho Econômico e Social do governo federal desde sua criação e presidir o Conselho de Governança do TPE desde a sua instituição. 
O significado deste intrincado processo de relações empresariais que toma conta de uma fatia do mercado educacional é justificado pelos empresários em torno de um discurso comum de 'qualidade da educação' e se constitui numa rede política que oferece para o sucesso dessa missão a competência gerencial, ou seja, para o Movimento é preciso “ajustar as políticas educacionais e as práticas institucionais e pedagógicas aos moldes da gestão empresarial, do mercado e da performatividade neoliberal" (VOSS, 2011, p. 53). E essa qualidade empresarial se baseia em princípios de eficiência e produtividade que possam ser mensuradas através de provas padronizadas aplicadas a estudantes de todo o país.

Configurando esta discussão de classe do Movimento Todos pela Educação, os empresários dão a direção e o conteúdo da política educacional e promovem o consenso em torno de metas e propostas. Vejamos algumas considerações sobre a influência e interlocução desses sujeitos privados e como se relacionam com o setor público na definição de políticas nacionais de educação na última década.

\section{DO TPE AO COMPROMISSO TODOS PELA EDUCAÇÃO: INTERLOCUÇÃO E HEGEMONIA DO MOVIMENTO EMPRESARIAL NA POLÍTICA EDUCACIONAL BRASILEIRA}

Nesta sessão apresentaremos algumas aproximações verificadas entre o setor privado e as políticas federais de educação. Em 2007, o Ministério da Educação (MEC), criou o Plano de Metas Compromisso Todos pela Educação e lançou o Plano de Desenvolvimento da Educação- PDE. Destacamos que este nome sugere que o governo incorporou o Movimento empresarial Todos pela Educação como já alertaram Dermeval Saviani (2007), Nora Rut Krawczyk (2000), Regina Cestari de Oliveira (2012), Olinda Evangelista e Roberto Leher (2012).

Saviani (2007) destacou que, ao capitalizar a receptividade da opinião pública já trabalhada pelos empresários por meio da mídia através do TPE, o governo pautou a importância de priorizar a educação, mas alertou que o MEC precisaria superar os limites da trilha proposta por esse Movimento, especialmente a pedagogia de resultados através das avaliações, para que o PDE/PAR pudesse avançar na sua proposta de qualificação da educação.

Registramos mais um argumento sobre essa proximidade de interlocução do TPE com o governo federal, que também é apontada pelo próprio Movimento Empresarial Todos Pela Educação, quando afirma, em notícia publicada na sua página em 13 de fevereiro de 2008, que 
O movimento Todos pela Educação é nacional, iniciado por um grupo de lideranças da sociedade civil em sintonia com o MEC, Consed (Conselho Nacional de Secretários da Educação) e Undime (União Nacional dos Dirigentes Municipais de Educação), numa parceria pioneira, onde o objetivo principal é garantir educação de qualidade a todas as crianças e jovens brasileiros até 2022, ano que o Brasil celebra o bicentenário da Independência. (TPE, 2014 - grifos nossos)

A escolha por chamar grandes entidades dirigentes educacionais para apresentar suas propostas busca construir o consenso do discurso do TPE com esses representantes dos governos nacionais, estaduais e municipais. Cabe ressaltar o que Lucia Camini (2013) já destacou: o MEC, ao elaborar o Plano de Desenvolvimento da Educação/Plano de Metas Compromisso Todos pela Educação (2007-2009), chamou para dialogar com o Fundo das Nações Unidas para a Infância (Unicef) - com quem realizara pesquisa em escolas com bons resultados que discrepavam dos resultados alcançados por escolas dos mesmos municípios - a Unesco, o Conselho Nacional de Secretários Estaduais de Educação Básica (Consed), a Undime e, por último, a Confederação Nacional Trabalhadores em Educação (CNTE). Ou seja, o diálogo do governo se deu com os mesmos sujeitos coletivos com os quais o TPE afirma ter sintonia.

Também podemos destacar que muitos sujeitos do governo estão no TPE (como é o caso do Ministro da Educação e dos ex-secretários de Educação Básica Maria do Pilar e Cesar Callegari), conforme já mostramos no quadro 1, da sessão anterior. Isso se traduz num nexo mais do que conjuntural e configurouse na opção de dialogar com empresários naquilo que podemos chamar de construção do "presidencialismo de coalizão" (VIEIRA, 2015) ou de conciliação para governabilidade em que os interlocutores dos movimentos educacionais, construtores das bandeiras de lutas da educação, muitas vezes são colocados em segundo plano.

Outro elemento que apartamos nesse contraditório processo é que, para formular estratégias de mobilização do programa, o Decreto no 6.094/2007 prevê a elaboração de um Comitê Nacional do Compromisso Todos Pela Educação, que será desdobrado em Comitês Locais. Esses comitês preveem a participação da sociedade civil, que engloba todos, dos empresários aos educadores). Para exemplificar as relações entre os sujeitos participantes desse processo, tomemos por base o Rio Grande do Sul que, segundo Lucia Camini (2013) descreveu, o Comitê Estadual de gestão do Plano de Metas Compromisso Todos pela Educação, coordenado por Marisa Abreu, teve a representação da Undime, do Conselho Estadual de Educação (Ceed), do Ministério Público, dos Conselhos Tutelares, do ex-ministro da educação Paulo Renato de Souza e dos representantes 
de associações de empresários, como o Instituto Gerdau e a Fundação Maurício Sirotsky Sobrinho. Ou seja, a parceria com empresários estava ocupando cada vez mais espaço nas relações com a política.

O Movimento Todos pela Educação, atuando em rede, possibilita uma mobilização maior entre os sujeitos, ora na proposição da política educacional, ora na mobilização para construir o consenso em torno das metas a serem alcançadas, ora na oferta de tecnologias educacionais e dos meios para atingir as metas. Assim, o TPE se constitui numa rede de empresas que oferta produtos, seja de forma direta, seja sob a forma de associados e ou apoiados pelos empresários, materializando a ampliação das relações da educação pública com o setor privado no Brasil.

Entendemos que o TPE configura-se como um movimento que "embaralha intencionalmente a linha divisória entre negócios, empreendimento, desenvolvimento e o bem público" (BALL; OLMEDO, 2013, p. 37) na medida em que, além da indicação de parceria com setor privado e empresarial, podemos observar que os mesmos sujeitos do movimento empresarial Todos pela Educação são agentes e interlocutores no setor público, junto ao Ministério da Educação, tornando-se clientes do Estado ao ofertarem produtos no Guia de Tecnologia ou recomendações.

Agora vejamos, na figura abaixo, as relações entre o Conselho de Governança do TPE, as instituições ligadas aos sujeitos explicitadas no Quadro 1 e as suas ofertas no Guia de Tecnologias Educacionais. 
Figura 1 - Sujeitos individuais e coletivos e relações com o guia de tecnologias

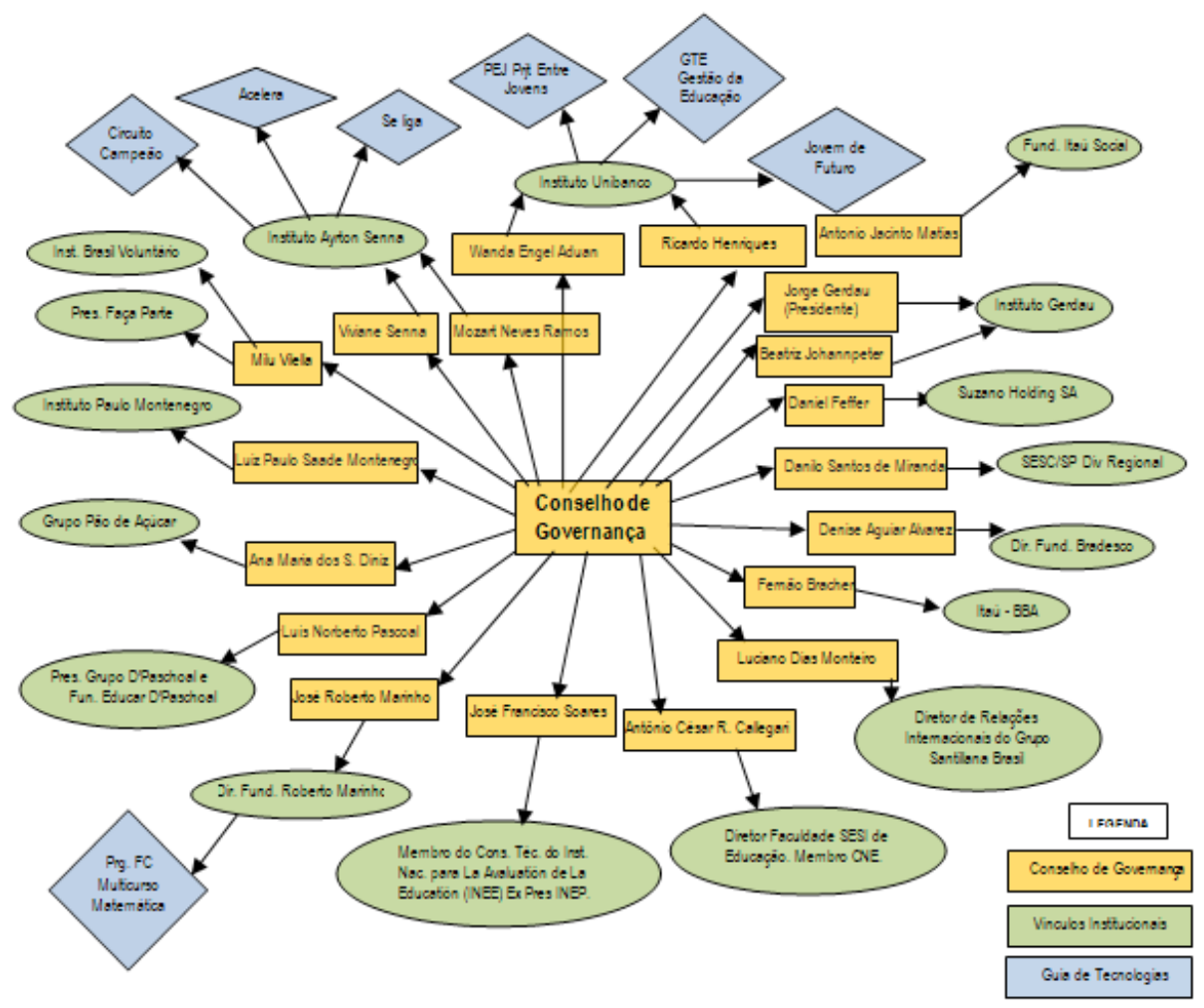

Fonte: arquivo próprio

Observando a figura acima, constatamos que os sujeitos e as empresas do Conselho de Governança do TPE oferecem tecnologias que constam do Guia de Tecnologias Educacionais, predominantemente em áreas essenciais: a) Aprendizagem, por meio dos programas Circuito Campeão, Acelera e Se Liga e Formação para o trabalho ${ }^{6}$; b) Projeto Entre Jovens e Jovem de Futuro. Esses exemplos ilustram não só a oferta de produtos das empresas, caracterizando as relações comerciais, como também ofertam tecnologias que influenciam na gestão da educação.

Nesse sentido, concordamos com Vera Peroni quando afirma que as políticas sociais passam a ser executadas pelo público não estatal - iniciativas

6 Trabalho compreendido conforme Evangelista e Leher (2012). 
particulares com sentido público: "O púbico que passa a ser de direito privado, ou o Estado faz parcerias com instituições do Terceiro Setor para a execução de políticas sociais" (PERONI, 2012, p. 17).

O modelo empresarial de gestão é apresentado como alternativa para a qualificação da educação. Tem crescido muito no país, nos últimos anos, esta guinada ao mercado ou à construção de um negócio educacional - Edu busines (BALL, 2012) - com a oferta de programas, cartilhas padronizadas e replicáveis, de softwares e de materiais didáticos para as escolas públicas. Essas políticas são ofertadas aos sistemas de ensino em todos os níveis com o discurso de qualificação da educação e chegam às escolas, desdobradas em várias possibilidades de parcerias (voluntários, privados, ONGs) para tratar dos problemas enfrentados nas instituições. Ou seja, a solução apontada está no mercado.

O Estado deve ser "regulador, incentivador e corretor de assimetrias" (AFONSO, 2002, p.53), diminuindo sua presença ao mesmo tempo em que reforça a "mobilização da comunidade e a iniciativa da sociedade civil" (ibidem). Aqui o conceito de sociedade civil é compreendido como uma expressão "mágica e adaptável" (WOOD, 2003, p. 208) a qualquer situação, melhor dizendo, a situação que interessa àqueles que estão no poder, sendo usada para identificar uma "arena fora do Estado" (ibidem). Nesse sentido, torna-se um conceito tão amplo e capaz de abranger todas as instituições e relações da economia capitalista, que vai desde o sindicato, os movimentos sociais, até as empresas privadas, identificando conforme seus interesses aqueles que detêm os meios de produção como sociedade civil. Nesse sentido, concordamos com a autora acima citada que, de certo modo, se "trata da privatização do poder público que criou um mundo historicamente novo da sociedade civil" (idem, p. 127), esvaziando assim a democracia como luta.

Este é um ponto chave para a compreensão do que afirmamos ao longo deste artigo: existe um forte movimento da classe empresarial dominante que, seguindo as recomendações do capitalismo internacional, construiu uma trajetória de interlocução com o Estado, influenciou a pauta educacional brasileira e tornou-se cliente, pois ao mesmo tempo em que estabelece o conteúdo de propostas e programas educacionais, oferta produtos tecnológicos para 'dar conta' de solucionar todos os problemas educacionais. Enquanto realiza intenso movimento de classe, usando a convocação da união de 'todos' na busca da qualidade da educação por ela definida, nega o conflito de classe para apaziguar a correlação de forças e constrói o consenso e sua manutenção em torno de suas definições. 
O quadro a seguir evidencia algumas bandeiras de luta dos movimentos sociais que foram incorporadas pelo TPE como metas suas e que, no processo de promoção de políticas, foram materializadas também na legislação educacional brasileira. Destacamos que não se trata de uma equivalência termo a termo ou de conversão das metas do TPE em programas e políticas educacionais, mas que, dada a relação estabelecida entre os empresários e o governo federal na discussão, elaboração e implementação das políticas, como já evidenciamos ao longo do texto, entendemos que há uma grande influência desse segmento.

\section{Quadro 2-Propostas do TPE e Políticas Governamentais}

\begin{tabular}{|l|l|}
\hline \multicolumn{1}{|c|}{ TPE } & \multicolumn{1}{|c|}{ POLITICAS GOVERNAMENTAIS } \\
\hline Meta 1- Toda criança e jovem de 4 a 17 anos na escola & $\begin{array}{l}\text { EC } 59 \text {-11/11/2009 } \\
\text { Lei } 12.796 \text { de 04/04/2013 (LDB) } \\
\text { Lei No 13.005 de 25/06/2014 - PNE }\end{array}$ \\
\hline $\begin{array}{l}\text { Meta 2- Toda criança plenamente alfabetizada até os 8 } \\
\text { anos }\end{array}$ & $\begin{array}{l}\text { Pacto Nacional pela Alfabetização na Idade Certa - } \\
\text { Portaria No 867, de 4/07/ 2012. } \\
\text { Lei No 13.005 de 25/06/2014 - PNE }\end{array}$ \\
\hline $\begin{array}{l}\text { Meta 3- Todo aluno com aprendizado adequado ao seu } \\
\text { ano }\end{array}$ & Política de Correção Fluxo - PAR/ GUIA \\
\hline $\begin{array}{l}\text { Meta 4- Todo jovem de 19 anos com Ensino Médio } \\
\text { concluído }\end{array}$ & $\begin{array}{l}\text { Pacto pelo Fortalecimento do Ensino Médio- Portaria } n^{\circ} \\
1.140, \text { de 22/11/2013 }\end{array}$ \\
\hline $\begin{array}{l}\text { Meta 5- Investimento em Educação ampliado e bem } \\
\text { gerido - Aperfeiçoamento da gestão e da governança da } \\
\text { Educação. }\end{array}$ & $\begin{array}{l}\text { 18 programas de gestão no Guia } \\
\text { Lei No 13.005 de 25/06/2014 - PNE }\end{array}$ \\
\hline
\end{tabular}

Fonte: arquivo próprio

As metas do TPE referendam o que o Education for All (EFA) já havia declarado. Considerando que o Brasil é signatário dessa declaração, não nos causa estranheza que suas políticas governamentais se aproximem dessas propostas. Por outro lado, lembramos que essas metas, estabelecidas tanto pelo EFA quanto pelo TPE, sempre estiveram presentes nas bandeiras de luta dos movimentos sociais educacionais como corrobora a Meta 1 do TPE. A ampliação do tempo de escolarização sempre foi reivindicação dos movimentos educacionais em defesa da escola pública e esta ideia é um consenso na sociedade brasileira e reconhecemos sua legitimidade. Porém, ao mesmo tempo em que consideramos um avanço a conquista da ampliação da escolarização, questionamos o interesse dos empresários por essa bandeira e o conteúdo da proposta por eles defendida.

Este conteúdo já referenciado, tais como a gestão gerencial, a avaliação em larga escala, a meritocracia, os produtos educacionais padronizados e replicáveis, é apresentado como soluções para os problemas educacionais, naturalizando o estabelecimento de parceria público-privada. Isso fica evidenciado na figura $1 \mathrm{e}$ no quadro acima, especialmente nas metas 3 e 5 , em que podemos constatar ter 
existido a indução à ampliação de parcerias e à oferta de produtos e tecnologias para alcançá-las presentes no Guia de Tecnologias Educacionais ofertados pelo PAR.

Ainda destacamos que as metas 2 e 4, propostas pelos empresários, podem ser associadas à criação de dois grandes Pactos Nacionais propostos pelo governo federal: um relacionado à alfabetização e outro ao Ensino médio, conforme exposto no quadro acima.

A questão que aqui se coloca e que demonstramos ao longo deste artigo é a presença maciça dos empresários por meio do TPE na relação com o Estado. Retomamos a ideia de que eles se apropriaram do discurso historicamente construído pelos movimentos sociais em defesa da escola pública gratuita e de qualidade e que, a sua materialização, vincularam seus interesses de classe.

\section{CONSIDERAÇÕES FINAIS}

Neste artigo, abordamos o Movimento Todos pela Educação, fundado por empresários, até o Compromisso Todos pela Educação criado pelo governo federal. Evidenciamos as possibilidades de parcerias público-privadas que se abrem a partir da elaboração do Plano de Ações Articuladas aos estados e municípios que assinaram o Compromisso, buscando destacar os caminhos pelos quais o setor privado adentra e influencia o setor público nas políticas educacionais, objetivando demonstrar o modo como a classe empresarial influenciou algumas políticas.

Vimos que os mesmos empresários que fundaram o TPE são interlocutores junto ao Estado na definição de políticas e colocam-se em outros espaços, como conselheiros e fornecedores, por meio da venda de produtos pedagógicos a partir do Guia de Tecnologias Educacionais.

Essa afirmação de poder de ação do grupo empresarial ligado ao TPE que, ao mesmo tempo é interlocutor que induz à definição de propostas e programas educacionais e torna-se cliente do Estado, pode ser definida como um movimento de classe. Os empresários colocaram o mercado como a solução para todos os problemas da educação e a lógica da gestão empresarial como a única alternativa de sucesso. Nesse sentido, entendemos que os empresários que constituem o TPE (como classe organizada) são os representantes da classe dominante. Os mesmos sujeitos que construíram um discurso socialmente aceito, apropriando-se das bandeiras de luta dos movimentos sociais e criando uma coalizão de interesses nas políticas educacionais brasileiras são os que irão ofertar o que consideram ser as 'soluções' para os 'problemas' da educação. 
Ao se constituírem em rede, os empresários em ação no Movimento Todos pela Educação, se não pautam diretamente as políticas como interlocutores diretos ou clientes, fazem-no na mediação, no apoio que oferecem a outras empresas que ofertam produtos ou que ajudam a determinar o tipo de qualidade educacional defendida por eles: medida, ranqueada e solucionada pelo mercado.

A ideia de hegemonia ficou evidente na medida em que os empresários enquanto classe, incorporam a seu discurso algumas bandeiras históricas, que ao mesmo tempo que arrefecem o conflito de classes, conseguem construir consenso em torno de ideias, ressignificando-as e imprimindo sua visão de qualidade pautada no mercado, que passa a ser parâmetro para as soluções aos problemas educacionais.

Ao mesmo tempo em que a política educacional, construída pelo governo através do PDE/PAR, amplia a presença do Estado no atendimento da Educação Básica, o Estado se alia ao TPE e reforça a lógica de que o mercado apresenta as soluções mais adequadas para melhoria da qualidade da educação.

\section{REFERÊNCIAS}

AFONSO, Almerindo Janela. O Neoliberalismo educacional mitigado numa década de governação social democrata. In. LIMA, Licinio C.; AFONSO, Almerindo Janela (orgs.) Reformas da Educação Pública: Democratização, Modernização e Neoliberalismo. Porto: Afrontamento, 2002.

BALL, Stephen. Global Education - New policy networks and the neoliberal imaginary Routledge- Londres - NY- 2012.

BALL, S. J.; OLMEDO, A. A 'nova' filantropia, o capitalismo social e as redes de políticas globais em educação. In: PERONI, Vera (org.). Redefinições das fronteiras entre o público e o privado: implicações para a democratização da educação. Brasília: Líber Livro, 2013, p. 33-47.

BRASIL. Guia de Tecnologias Educacionais 2011/12/organização COGETEC. Brasília: Ministério da Educação, Secretaria de Educação Básica, 2011, 196 p.

BRASIL. Plano de ações articuladas - PAR- 2011-2014. Guia prático de ações para municípios. Brasília: Ministério da Educação, 2011. 
BRASIL. Decreto $\mathbf{n}^{\mathbf{0}} \mathbf{6 . 0 9 4}$, de 24 abril de 2007. Dispõe sobre a implementação do Plano de Metas Compromisso Todos pela Educação, pela União Federal, em regime de colaboração com Municípios, Distrito Federal e Estados, e a participação das famílias e da comunidade, mediante programas e ações de assistência técnica e financeira, visando a mobilização social pela melhoria da qualidade da educação básica.

CAMINI, Lucia. Política e Gestão Educacional Brasileira. São Paulo: Outras Expressões, 2013.

EVANGELISTA, Olinda; LEHER, Roberto. Todos pela Educação e o Episódio Costin no MEC: A Pedagogia do Capital em Ação na Política Educacional Brasileira. Trabalho Necessário-www.uff/trabalhonecessario. Ano $10, n^{\circ} 15,2012$.

GALE, Trevor. Realising Policy: The Who na how of policy production. In Lingard, Bob; OZGA, Jenny. The Routledge Falmer Reader in Education Policy and Politics. Milton Park, England: Routledge, 2007.

GRAMSCI, Antonio. Cadernos do Cárcere. Vol.3.3 ${ }^{\mathrm{a}}$ Ed, Rio de Janeiro: Civilização Brasileira, 2002.

KRAWCZYK, Nora. A construção social das políticas educacionais no Brasil e na América Latina. In: KRAWCZYK, Nora; CAMPOS, Maria M.; HADDAD, Sérgio (org.). O cenário educacional latino-americano no limiar do século XXI: reformas em debate. São Paulo: Autores Associados, 2000, p. 1-11.

LAVAL, Christian. A escola não é uma empresa: o neoliberalismo em ataque ao ensino público. Londrina: Planta, 2004.

LIMA, Licinio C. Aprender para ganhar, conhecer para competir: sobre a subordinação da educação na 'sociedade do conhecimento'. São Paulo: Cortez, 2012.

MARTINS, Andre Martins. A Educação Básica no século XXI: o projeto do organismo 'Todos Pela Educação'. Praxis Educativa, Ponta Grossa, vol.4, no 1 , 
MARTINS, Erika Moreira. Movimento Todos Pela Educação: um projeto de nação para a educação Brasileira. Campinas: URCAMP, 2013. Dissertação de Mestrado, Faculdade de Educação, Universidade Regional de Campinas, 2013.

OLIVEIRA, Regina Tereza Cestari de. O Plano de Ações Articuladas em municípios sul-mato-grossenses e suas implicações para a gestão democrática da educação básica. Acta Scientiarum. Education, Maringa, vol34, n², p.291-300, July-Dec,2012.

OZGA, Jenny; LINGARD, Bob. Globalization, Education Policy and Politics. In Lingard, Bob; OZGA, Jenny. The Routledge Falmer Reader in Education Policy and Politics. Milton Park, England: Routledge, 2007.

PERONI, Vera. Mudanças no papel do Estado e políticas públicas de educação: notas sobre a relação público/privada. In: PERONI, Vera; ROSSI, Alexandre (orgs.). Políticas educacionais em tempos de redefinição do papel no Estado: implicações para a democratização da educação. Porto Alegre: PPGEdu UFRGS; Pelotas: UFPEL, 2011, p. 23-41.

A gestão democrática da educação em tempos de parceria entre o público e o privado. Revista proposições. UNICAMP, vol.23, n². Campinas maio/ago, 2012.

PIRES, Daniela de Oliveira. A construção histórica da relação públicoprivada na promoção do direito à educação no Brasil. Porto Alegre: UFRGS, Tese de Doutorado, Faculdade de Educação, Universidade Federal do Rio Grande do Sul, 2015.

ROSSI, Alexandre José. Avanços e limites da política de combate à homofobia : uma análise do processo de implementação das ações para a educação do Programa Brasil Sem Homofobia. 2010. 186 f. Dissertação (Mestrado) - Curso de Faculdade de Educação, Universidade Federal do Rio Grande do Sul, Porto Alegre, 2010. 
ROSSI, Alexandre; BERNARDI, Liane Maria; UCZAK, Lucia Hugo. Relação Público- Privada no Programa de Desenvolvimento da Educação: uma análise do Plano de Ações Articuladas. In: PERONI, Vera; (org.). Redefinições das Fronteiras entre o Público e o Privado: Implicações para a democratização da educação. Brasília: Liber Livros, 2013.

SAVIANI, Dermeval. Plano de Desenvolvimento da Educação: análise do projeto do MEC 2007. Educação e Sociedade, Campinas, vol.28, n¹00- Especial, p.1231-55, out 2007 .

SHIROMA, Eneida Otto; GARCIA, Rosalba Maria Cardoso; CAMPOS, Roselane Fatima. Conversão das “almas” pela liturgia da palavra: uma análise do movimento Todos pela Educação. In: BALL, Stephen J.; MAINARDES, Jefferson. Políticas educacionais: questões e dilemas. São Paulo: Cortez, 2011.

SOUZA, Paulo Renato. Educação e responsabilidade social. Folha de São Paulo. Opinião. 16/06/2006. Disponível em:http://www1.folha.uol.com.br/fsp/ opiniao/fz1906200608.htm. Acesso em 06 de setembro de 2016.

THOMPSON, E. P. A miséria da teoria ou um planetário de erros. Uma crítica ao pensamento de Althusser. Rio de Janeiro: Zahar, 1991.

A Formação da Classe Operária Inglesa. Vol.1. Rio de Janeiro: Paz e Terra, 1987.

TPE. Todos pela Educação - http:/ /www.todospelaeducacao.org.br - Acesso em 20/05/2015.

http://www.todospelaeducacao.org.br/educacao-na-midia/indice/574), Acesso em 10/09/2014.

VIEIRA, Evaldo. Os direitos sociais e a política social. São Paulo: Cortez, 2007.

. A República Brasileira 1951-2010 de Getúlio a Lula. São Paulo: Editora Cortez, 2015. 
VOSS, Dulce Mari da Silva. O Plano de Desenvolvimento da Educação( PDE): contextos e discursos. Pelotas: Cadernos de Educação: FaE/PPGE/UFPel: Janeiro/abril, 2011.

WOOD, Ellen Meiksins. Democracia contra capitalismo: a renovação do materialismo histórico. São Paulo: Boitempo Editorial, 2003.

ALEXANDRE JOSÉ ROSSI é doutor em Educação pela Universidade Federal do Rio Grande do Sul (UFRGS) e pesquisador vinculado ao Núcleo de Estudos de Política e Gestão da Educação atuando no Grupo de Pesquisa: Relações entre o Público e o Privado na Educação (GPRPPE). E-mail: ajrossi.rossi@gmail.com

LIANE MARIA BERNARDI é doutora em Educação pela Universidade Federal do Rio Grande do Sul (UFRGS), professora aposentada da Rede Pública Municipal de Porto Alegre, vinculada ao Núcleo de Estudos de Política e Gestão da Educação atuando no Grupo de Pesquisa: Relações entre o Público e o Privado na Educação (GPRPPE). E-mail: lianebernardi@gmail.com

LUCIA HUGO UCZAK é doutora em Educação pela Universidade Federal do Rio Grande do Sul (UFRGS), docente na Universidade Feevale, vinculada ao Núcleo de Estudos de Política e Gestão da Educação atuando no Grupo de Pesquisa: Relações entre o Público e o Privado na Educação (GPRPPE). E-mail: lucia. hugo@yahoo.com.br 